\title{
Assessment and analysis of groundwater overexploitation in China
}

\author{
Zepeng $\mathrm{Li}^{1}$, Xin $\mathrm{He}^{1,}{ }^{*}$, Chuiyu $\mathrm{Lu}^{1}$ \\ ${ }^{1}$ China Institute of Water Resources and Hydropower Research, Beijing 100038, China
}

\begin{abstract}
As an important water resource, groundwater has been unreasonably developed for a long time in our country, causing a lot of problems. This paper combines the data from the national groundwater monitoring stations and the groundwater depth data collected locally to statistics and analysis of groundwater overexploitation across the country. Especially in key plains, through the water level variation method. The research results are compared and verified with national authoritative data such as Groundwater Dynamics Monthly Report and predecessors' records in the literature, revealing the current key areas of groundwater overexploitation, and clarifying the importance and urgency of groundwater governance in the future. This study also put forward some suggestions of groundwater overexploitation.
\end{abstract}

\section{Introduction}

Groundwater resources play an indispensable role in social and economic development, food security, and drinking water safety. In China water resources are unevenly distributed in the north and south, and the total amount of water resources is deficient seriously. As a reliable source of water supply, groundwater plays an important role in ensuring water security. In order to meet the needs of population growth and economic development, some water-scarce areas have long been over-exploiting groundwater. The continuous overdraft of groundwater has caused a series of ecological, geological, and environmental problems, resulting in the loss of economic and environmental resources [1-2]. At present, there are many research conclusions on groundwater overexploitation areas in China. The total area of overexploitation areas in Hebei Province is $66,700 \mathrm{~km}^{2}$, accounting for more than $91 \%$ of the area of Hebei Plain (Wen, R.P., 2015). The total of groundwater overdrawn areas in Jiangsu Province is about $16,500 \mathrm{~km}^{2}$ (Huang, X.Y. et al., 2014a). The total of overdrawn area in Inner Mongolia Autonomous Region amounts to 7,200 km (Wang, P. et al., 2016) [3-5]. However, most studies tend to lack overall statistics and analysis. Therefore, a comprehensive assessment and analysis of the status of groundwater overexploitation across the country is extremely important for the sustainable development and utilization of water resources in China.

\section{Research methods and data}

\subsection{Data source}

The main data source of this study is the national groundwater monitoring data recorded in the China Geological Environment Monitoring Groundwater Yearbook (hereinafter referred to as the yearbook) in 2006 and 2016[6]. The groundwater monitoring wells in the Yearbook are spatially uneven in terms of regional distribution. This spatial distribution is directly related to the utilization of groundwater in the local area: Areas where groundwater is used frequently are also densely distributed with observation wells. The number of monitoring wells from 2006 to 2016 was relatively stable, with a total of 986 and 967 respectively. The number of monitoring wells for shallow or confined aquifer has remained roughly the same for ten years.

On the basis of the national site data in the Yearbook, this study will also analyze the groundwater level changes in main groundwater basins of China. Including the Huanghuaihai Plain, Songliao Plain, Fenwei Plain, Hetao Plain, Jianghan Plain and other regions can basically cover the key groundwater basins in China, where are also areas that are prone to groundwater overexploitation. Targeted analysis of the key basins areas is helpful to grasp the changes of groundwater on a smaller spatial scale. Add local observation well data to several key areas including 334 new observation wells for shallow groundwater and 168 for confined groundwater in the Huanghuaihai Plain; 222 new shallow observation wells in the Hetao Plain, and 87 shallow observation wells in the Songliao Plain. In order to ensure that the coastline confined groundwater depth remains at 0 after the interpolation, 80 points with a depth of 0 are artificially set along the coastline of the nation.

\subsection{Interpolation method}

The national groundwater depth is interpolated by the method of Kriging. Kriging is a more commonly used

*Corresponding author: hex@iwhr.com 
spatial interpolation method in geostatistics. It is based on the principle of regionalized variables and combined with the function of variability, under the premise of ensuring that the estimated value meets the condition of unbiasedness and minimum variance, get an estimate. In this study, the kriging interpolation variogram is a linear function to ensure not produce a nugget effect. Using no drift type, so the entire interpolation process will remain ordinary kriging. Because of the limited amount of data, the search radius setting selects using all data. The grid size of the is $20 \mathrm{~km}$ during calculate national raster, and the minimum value of the $Z$ value is set to 0 to prevent the groundwater depth of the interpolation value from being negative; while dealing with a single plain area, the grid size is $5 \mathrm{~km}$.

\subsection{Calculation of water level variation}

According to the National Technical Outline for Evaluation of Groundwater Overexploitation Areas (hereinafter referred to as the Outline), the average annual rate of change of groundwater level on the grid is calculated as follows:

$$
v=\frac{H_{1}-H_{2}}{\Delta t}
$$

In the formula: $v$ is the average annual groundwater level change rate (m/year); $H 1$ is the initial year groundwater level (m); H2 is the current year groundwater level (m); $\Delta t$ is the time period, here is 10 years.

This study used groundwater depth, the principle is the same as that of water level. According to raster calculator of ArcGIS to make the difference between the two groundwater depth grids and divide by the corresponding year to get the annual rate of change, finally got a plane result.

Taking into account the large scale of this study, the groundwater decline rate obtained on the grid is further calculated on the average change of the prefecture-level city, and the average annual change of a certain city as a whole is judged based on this. Through the Zonal statistical tools in ArcGIS, the average groundwater depth of a prefecture-level city is obtained according to the arithmetic average method:

$$
h=\left(x_{1}+x_{2}+x_{3}+\cdots+x_{n}\right) / n
$$

Among them, $\mathrm{h}$ means ground depth in a city, $\mathrm{x} 1$, $\mathrm{x} 2$...xi are the ground depth of each grid values of the city area, $\mathrm{n}$ is the number of grid in the city area.

Using the above methods to obtain the buried depth of each city in 2006 and 2016, and calculate the annual change rate of each city.

\subsection{Judgment of groundwater overdrawn area}

According to the outline requirements: For shallow groundwater, a decrease of less than $1.0 \mathrm{~m} /$ year belongs to a general overdrawn area, and greater than $1.0 \mathrm{~m} /$ year is a serious over-exploitation area; For deep confined water, less than $2.0 \mathrm{~m} /$ year is a general overdrawn area, and greater than $2.0 \mathrm{~m} /$ year It belongs to a serious overdrawn area.

\section{Results}

\subsection{Overview of groundwater overexploitation of the nation}

Count the area of the summary grid according to the standard in section 2.4, the statistics of over-exploitation area in each province are shown in Table 1. It can be seen from the table that over-exploitation areas are concentrated in Hebei Province, Shandong Province, Henan Province, and the three northeastern provinces, accounting for $27.67 \%, 24.84 \%, 17.60 \%$, and $10.81 \%$ of the country's total over-extraction areas. The four regions together account for about the $81 \%$ of the total area of overexploitation. The area of over-exploitation in all provinces of the nation is approximately $258,000 \mathrm{~km}^{2}$.

Table1. Statistics of over-exploitation area in various provinces (Unit:10,000 $\mathrm{km}^{2}$ )

\begin{tabular}{ccccccccc}
\hline Province & $\begin{array}{c}\text { Shallow } \\
\text { general } \\
\text { overdrawn }\end{array}$ & $\begin{array}{c}\text { Shallow } \\
\text { serious } \\
\text { overdrawn }\end{array}$ & $\begin{array}{c}\text { Shallow } \\
\text { total }\end{array}$ & $\begin{array}{c}\text { Confined } \\
\text { general } \\
\text { overdrawn }\end{array}$ & $\begin{array}{c}\text { Confined } \\
\text { serious } \\
\text { overdrawn }\end{array}$ & $\begin{array}{c}\text { Confined } \\
\text { total }\end{array}$ & Repeat & $\begin{array}{c}\text { Total } \\
\text { overdrawn }\end{array}$ \\
\cline { 2 - 8 } Beijing & 0.04 & 0.06 & 0.1 & 0.24 & & 0.24 & 0.04 & 0.3 \\
Tianjin & 0.04 & & 0.04 & 0.08 & 0.19 & 0.27 & & 0.31 \\
Hebei & 2.63 & 0.7 & 3.33 & 3.78 & 0.75 & 4.53 & 0.72 & 7.14 \\
Shanxi & 0.79 & 0.3 & 1.09 & 0.72 & & 0.72 & 0.2 & 1.61 \\
Inner & 0.1 & & 0.1 & 0.35 & 0.21 & 0.56 & 0.06 & 0.6 \\
Mongolia & & & 0.19 & 0.08 & & 0.08 & 0.08 & 0.19 \\
Liaoning & 0.19 & & 0.47 & & 0.47 & & 0.71 \\
Jilin & 0.2 & 0.04 & 0.24 & 0.47 & & 1.18 & & 1.69 \\
Heilongjiang & 0.51 & & 0.51 & 1.18 & & 4.41 & 0.07 & 6.41 \\
Shandong & 1.02 & 1.05 & 2.07 & 3.04 & 1.37 & 1.27 & 0.18 & 4.54 \\
Henan & 2.2 & 1.25 & 3.45 & 1.27 & & & 1.87 \\
Shaanxi & 0.08 & & 0.08 & 1.31 & 0.48 & 1.79 & & 0.43 \\
Gansu & 0.2 & 0.12 & 0.32 & 0.11 & & 0.11 & & \\
\hline
\end{tabular}

\subsection{Over-exploitation in key groundwater basins}

On the basis of collecting and sorting out the data of national observation sites in the Yearbook, combined with local groundwater data, the interpolation of groundwater depth are carried out on the Huanghuaihai Plain, Songliao Plain, Hetao Plain, Fenwei Plain, Jianghan Plain Respectively. 
The Huanghuaihai Plain is one of the three major plains in China and an important part of the Great Plains in Northeast China. The North China Plain is rich in groundwater storage, mainly in the loose layers of the Quaternary System. The groundwater overexploitation in the Huanghuaihai Plain is shown in Figure 1.

The Huanghuaihai Plain has general overdrawn area of $38,900 \mathrm{~km}^{2}$ and serious overdrawn area of $6,800 \mathrm{~km}^{2}$ mainly in the middle and western part of Hebei, the junction of Henan and Hebei, and the middle of Shandong. The confined water in the Huanghuaihai Plain is generally overdrawn in an area of about $69,400 \mathrm{~km}^{2}$, which is mainly concentrated in Tianjin, Hebei and Shandong. The area of serious overdrawn area is about $26,300 \mathrm{~km}^{2}$ mainly distributed in the central area of the general overexploitation area. After finishing zonal statistics in ArcGIS, raster values will be weighted average within each city polygon, then each city gets a regional annual change. The shallow overdrawn area has a more serious decrease in some region, which is $0.70 \mathrm{~m} / \mathrm{year}$ in Tai'an city, Shandong province. As for confined aquifer, Shijiazhuang has 0.51 $\mathrm{m} /$ year decrease, Cangzhou $1.78 \mathrm{~m} /$ year decreas.

The Songliao River Basin mainly includes parts of the Inner Mongolia Autonomous Region and the Northeast Plain. The West Liaohe River Basin and the Northeast Plain of Inner Mongolia are both important grain production areas in my country. However, with the increase of rice planting area and the shortage of total water resources, the current planting scale has obviously exceeded the carrying capacity of water resources in the region. As a result, groundwater in the plain area of the basin continued to decline. The study found that the overexploitation area of shallow groundwater in the Songliao River Basin is about $11,700 \mathrm{~km} 2$, mainly distributed in Chifeng City in the Xiliao river Basin; the area of overexploitation of deep groundwater is 10,300 $\mathrm{km} 2$, mainly distributed in the Sanjiang Plain in Heilongiiang Province and Liaoning Around Shenyang city. The groundwater overexploitation in the Songliao Plain is shown in Figure 2.

Fenwei plain is the fourth largest plain in China and the largest alluvial plain in the middle reaches of the Yellow River. The general overdrawn area of groundwater in the Fenwei Plain is about $11,800 \mathrm{~km}^{2}$, mainly distributed near Sanmenxia and Xi'an city. The overdrawn area of confined water is about $12,800 \mathrm{~km}^{2}$. On the scale of prefecture-level cities, Yuncheng's shallow aquifer groundwater level decreased by $0.47 \mathrm{~m} /$ year annually, and Sanmenxia City continued to decrease by $0.82 \mathrm{~m} / \mathrm{year}$. The groundwater overexploitation in the Fenwei Plain is shown in Figure 3.

The Hetao Plain is located in the Inner Mongolia Autonomous Region and Ningxia Hui Autonomous Region. It is an alluvial plain along the banks of the Yellow River. Jianghan Plain is located in the central and southern part of Hubei Province, it is an important part of the plains in the middle and lower reaches of the Yangtze River. According to the current data on the groundwater level in the Hetao Plain and Jianghan Plain, the water level in this area has been basically stable for many years, and there has been no over-exploitation of groundwater.

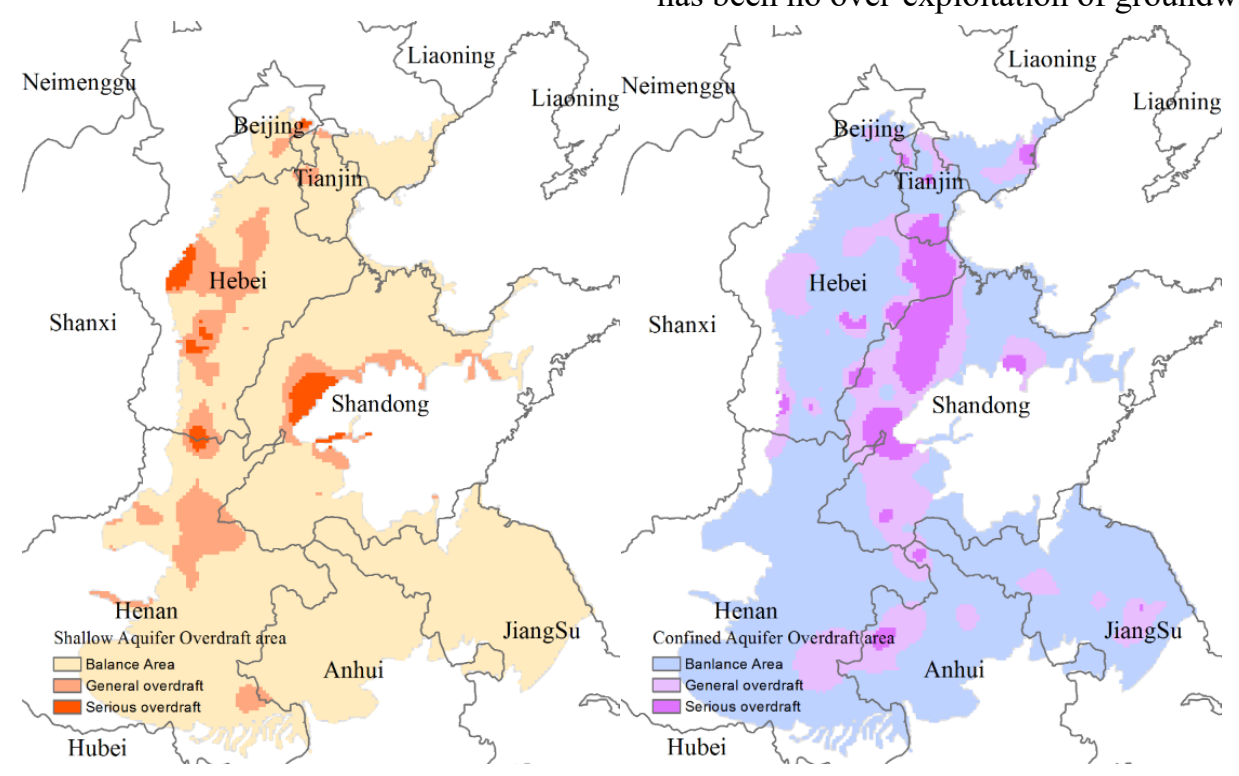

Fig1. Groundwater overexploitation in the Huanghuaihai Plain 


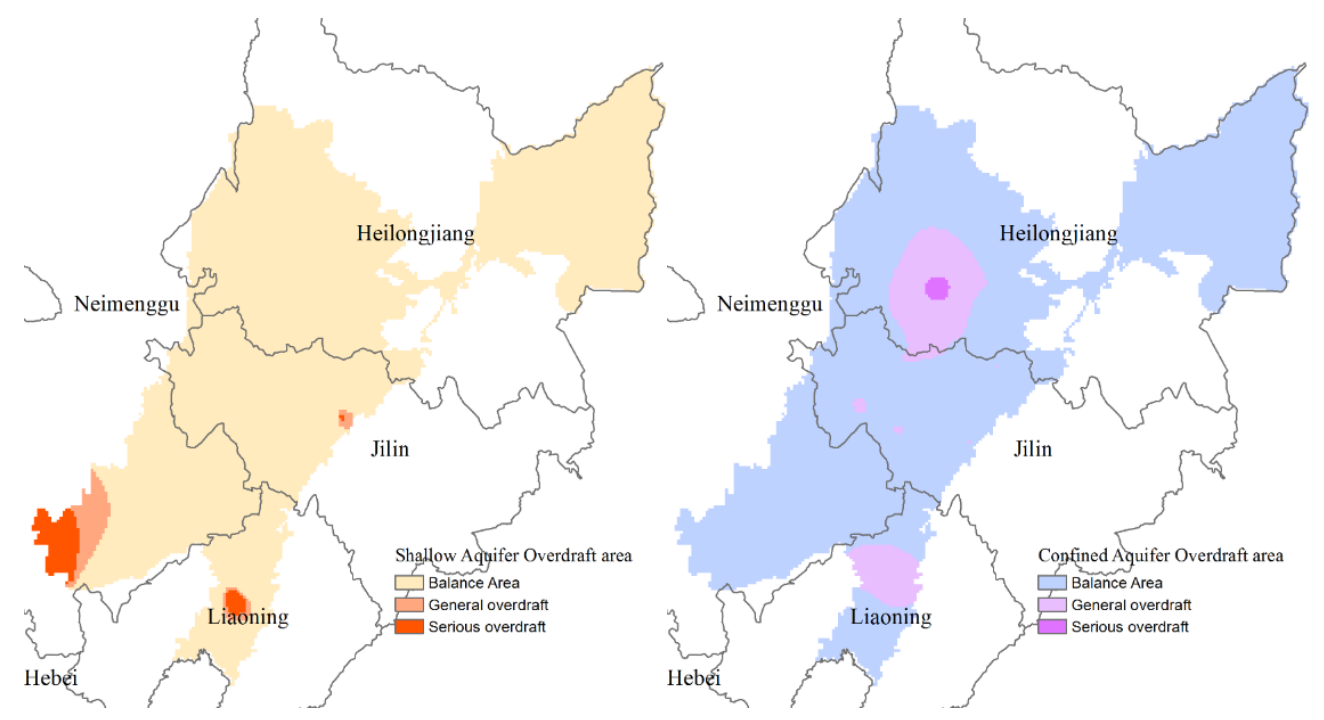

Fig2. Groundwater overexploitation in the Songliao Plain
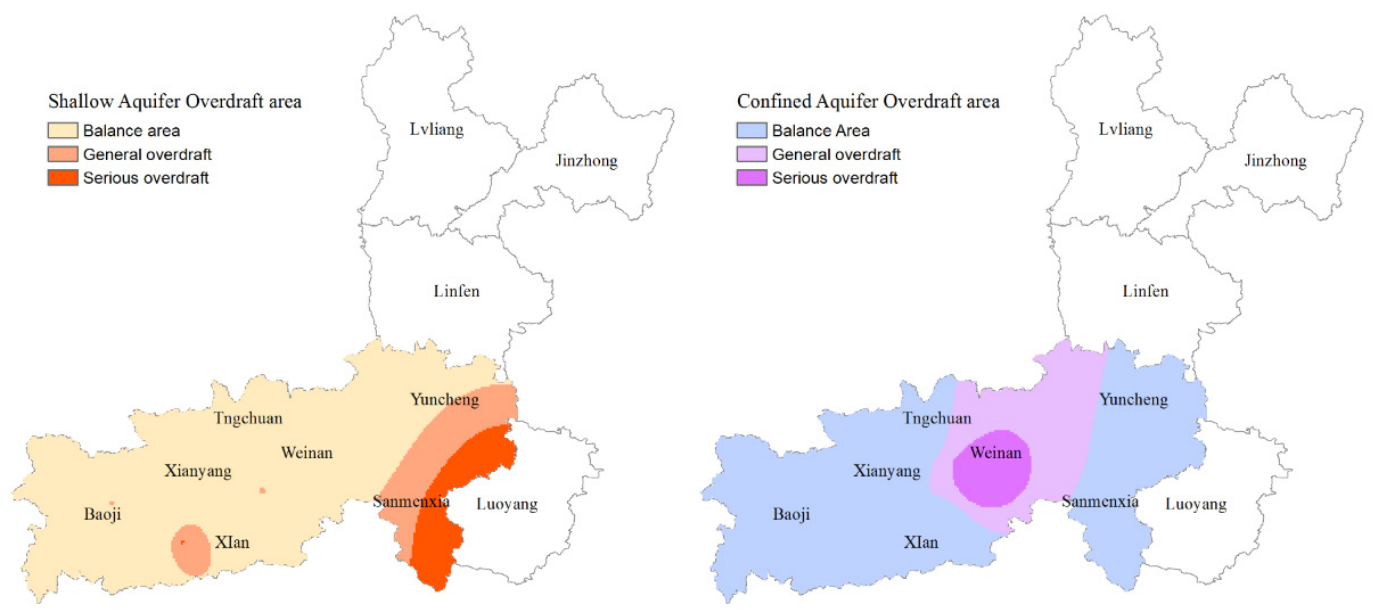

Fig3. Groundwater overexploitation in the Fenwei Plain

show in Figure4.

\section{Verification and comparison of calculation results}

\subsection{Check with Monthly Report of Groundwater Dynamics}

The National Monthly Report of Groundwater Dynamics (hereinafter referred to as Monthly Report) is issued by the Hydrological Department of the Ministry of Water Resources once a month. which major in groundwater basins, especially the Huanghuaihai Plain, Songliao Plain. In this study, the Huanghuaihai Plain was selected, and the results of the groundwater depth interpolation in December 2016 were used for verification with the Monthly Report. The shallow groundwater depth obtained in this study is basically the same as the Monthly Report for the same period. The results show that the shallow groundwater funnel of the Huanghuaihai Plain is located in Shijiazhuang City and spread to other areas. Result as

\subsection{Check with Water Resources Bulletin}

The variation of shallow aquifer depends on changes in groundwater recharge and discharge. If the groundwater recharge is less than the discharge, the diving depth of the landing funnel area will increase. This study compiled the data of the China Water Resources Bulletin from 2006 to 2016 in the main plains of the country. Through the analysis of recharge (precipitation) and discharge (groundwater supply, agricultural mining groundwater), indirectly verify the area of groundwater overexploitation area. Bulletin data statistics are shown in the figure 5.

The rainfall of Haihe Basin in 2016 increased by about 60 billion $\mathrm{m} 3$ compared with 2006.In the case of increased rainfall, the recharge of shallow groundwater will increase correspondingly, which has relieved the overexploitation of shallow groundwater to a certain extent. The basic trend of groundwater resources is roughly the same as rainfall. The proportion of agricultural water use and the proportion of groundwater in the total water supply of 
Haihe Basin are on an overall downward trend. The precipitation of 2016 was slightly more than that in 2006 and the amount of groundwater supply decreased. Therefore, it can be proved that overexploitation of groundwater is in a moderating situation in this area. Combined with the calculation of this overexploitation range, it can be concluded that the groundwater overexploitation in the southern part of the Huanghuaihai Plain (near the Huaihe) is better than that in the north (near the Haihe), which can be mainly attributed to the increase in precipitation and the decrease in groundwater usage.

The precipitation of Songliao Plain fluctuates around the multi-year average, with the least rainfall in 2007 and the most in 2013. The increase in rainfall has led to an increase in the amount of groundwater resources, But the increase of water resources has not effectively alleviated the problem of overexploitation in this area. This is mainly because the amount of groundwater supply has been increasing, which is reflected in the substantial increase in the rice planting area in the Songliao Plain. As the use of surface water resources is restricted by factors such as seasons and water conservancy facilities, the proportion of well irrigation in the Songliao Plain has increased significantly during this period, and the proportion of agricultural water used has continued to increase for many years.

\subsection{Check with literatures}

For the total area of overdrawn groundwater in the nation, different documents give different statistical results: Wang, X.J et al. published an article in 2013 that recorded a total of $180,000 \mathrm{~km}^{2}$ of overdrawn areas nationwide [7]. $\mathrm{Mu}$, E.L et al. discussed the total overdrawn area nearly $300,000 \mathrm{~km}^{2}$ in 2017 [8]. The result of this study is 258,000 $\mathrm{km}^{2}$, which lies between the two and can be considered reasonable.
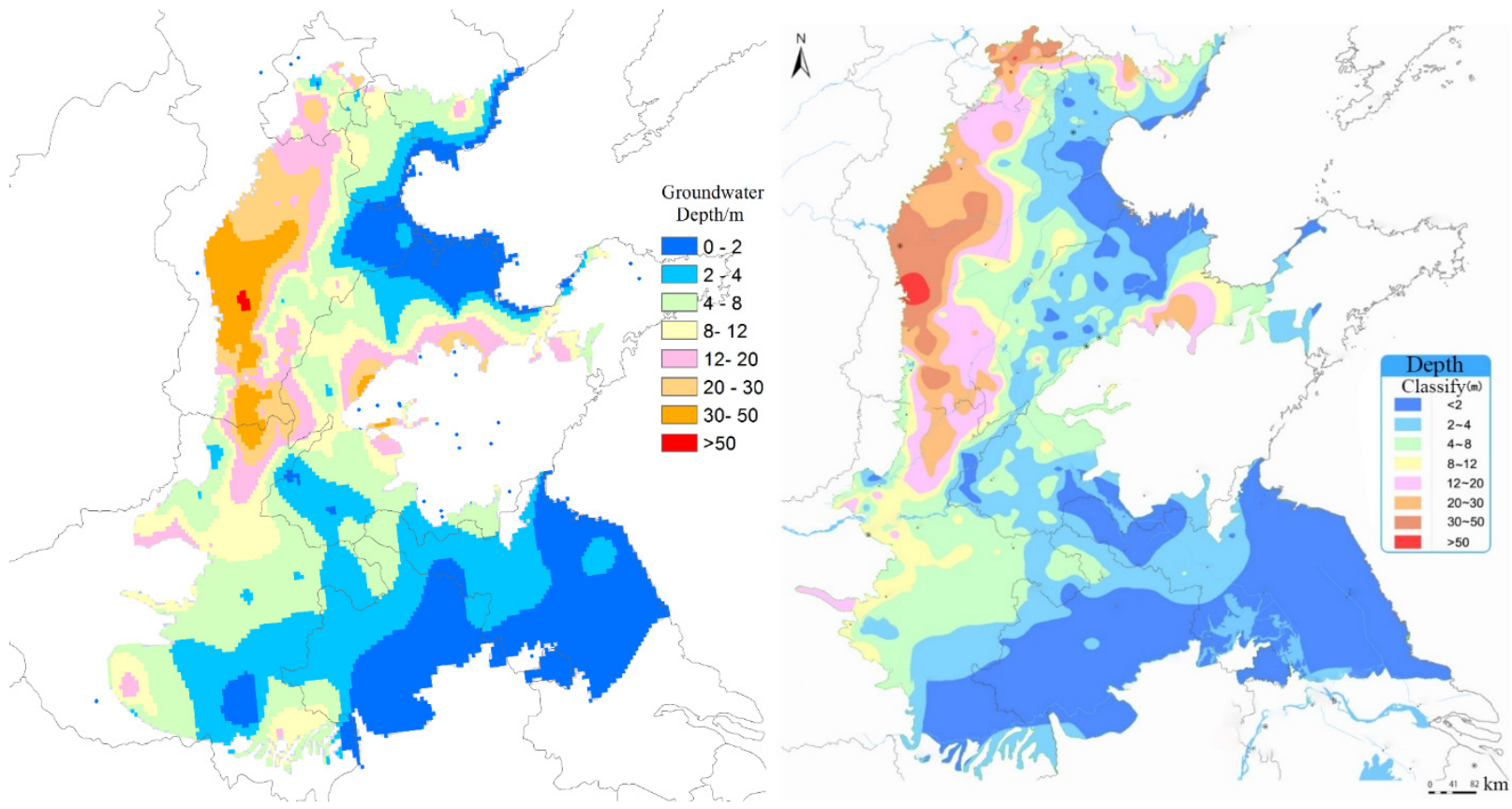

Fig4. Groundwater depth in 2016.12

(The picture on the left is the calculation of this study, and the picture on the right is taken from the monthly report)

Huaihe Basin

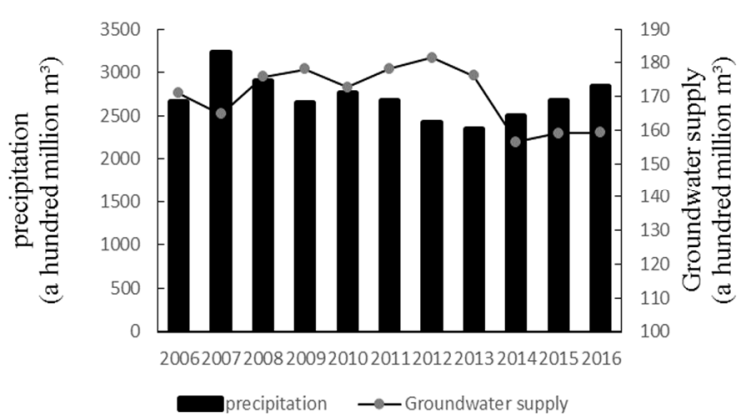

Haihe Basin

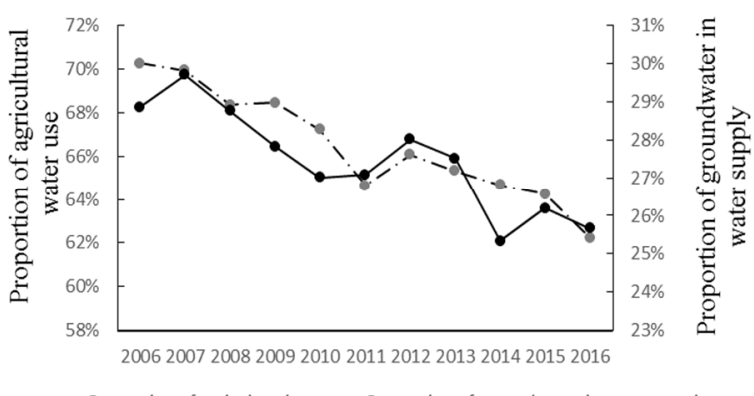


Haihe Basin

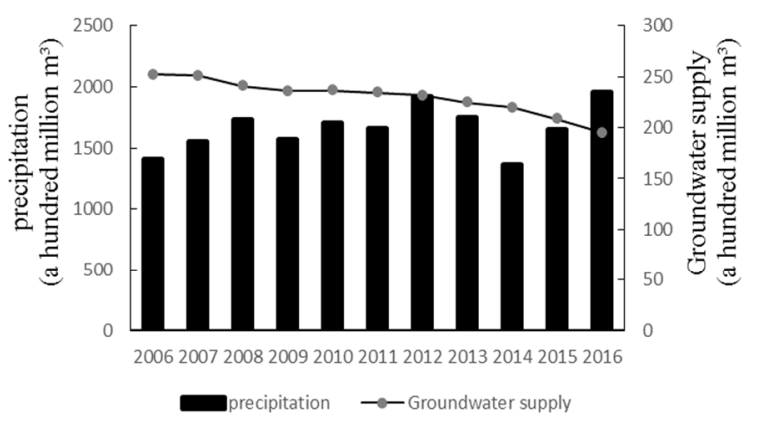

Songliao River Basin

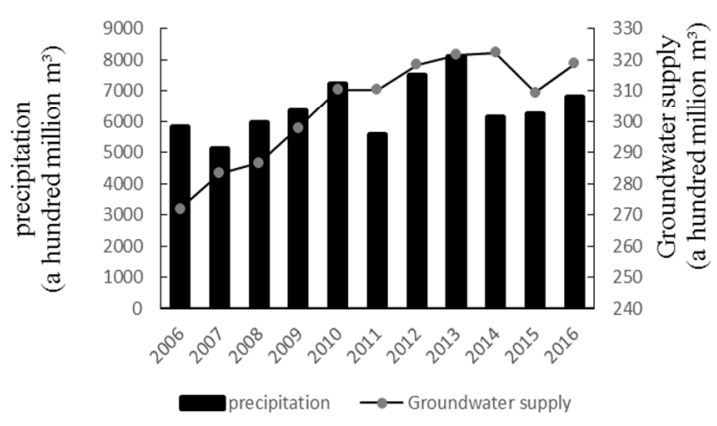

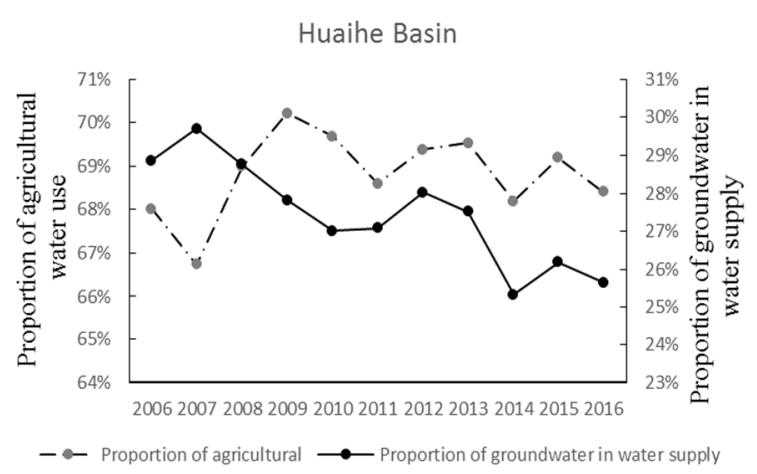

Songliao River Basin

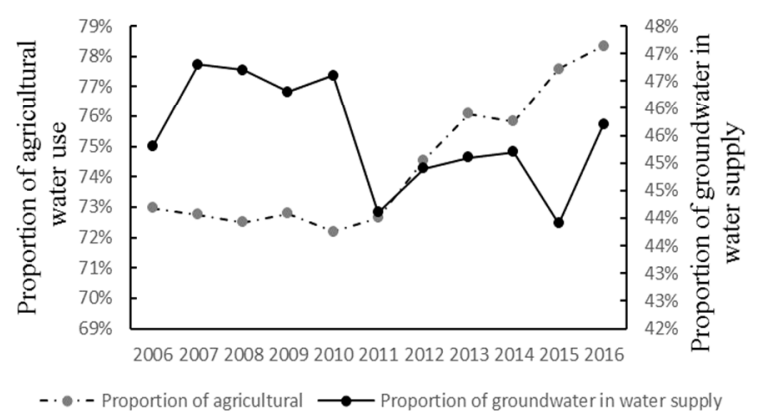

Fig5. Key basin data of Water Resources Bulletin

\section{Uncertainty discussion and conclusion}

In general, the conclusions of this study are consistent with previous studies, but there are also uncertainties : first, the national observation sites are unevenly distributed, even if with the local data collected above, the overall number of samples is still insufficient; Secondly, "artifacts" are inevitably appearing in interpolation using the Kriging method; In addition, due to the lack of latitude and longitude coordinates, some observation data can only be estimated by location, which also leads to errors.

This article uses the dynamic method of water level to grasp the situation of groundwater overexploitation in key areas of our country on a macro level, and compares it with previous records in the literature, and draws the following conclusions: (1) From a national perspective, the main The groundwater overdrawn areas in China are still concentrated in North China and Northeast China, which is consistent with past perceptions. The main reason for over-exploitation is agricultural irrigation. The type of crop (irrigation amount) is directly related to the degree of over-exploitation. (2) In the North China Plain, the problem of groundwater overexploitation in Hebei Province has been highly valued in the past. However, this study found that the problem of over-exploitation in Shandong and Henan provinces cannot be ignored either. (3) The problem of overexploitation in Northeast China should be vigilant, especially at the junction of northern Heilongjiang and Inner Mongolia. (4) The overexploitation of confined aquifer should arouse great attention. In North China, Songliao, Fenwei Plain and other places, the area of confined water overdraft has approached or even exceeded that of shallow water.
The problem of data is the basis for the evaluation of overexploitation, and it is also the biggest difficulty of this study. In the future, local groundwater monitoring stations should be appropriately increased which also contribute to prevent groundwater overexploitation in advance.

\section{Acknowledgments}

This work was financially supported by National Key Research and Development Program of China (grant No. 2016YFC0401404) and Applied Technology Research and Development Program of Heilongjiang Province (grant No.GA19C005)

\section{References}

1. Wu, A.M., Jing, J. h., Song, B., (2016) A brief discussion on China's water security issues and the protection of groundwater[J]. Acta Geology, 90(10):2939-2947.

2. Zhong, H. P., Bian, J. Y., (2007) The protection and management of groundwater in our country should be paid attention to $[\mathrm{J}]$. Science and Technology Review, 03: 70-73.

3. Wen, R.P., (2015) Overexploitation of groundwater in Hebei Province and its harm and treatment $[\mathrm{J}]$ Water Science and Technology and Economy, 21(12): 10 12.

4. Huang, X.Y., Feng, Z.X., Li, L., Liu, X.L., (2014). Change trend analysis of groundwater overexploitation area in Jiangsu Province[J]. Groundwater, 36(4):53-86.

5. Wang, P., Guo, Z.K., Li, L., (2016) Inner Mongolia 
groundwater over-exploitation area division and management recommendations[J]. Inner Mongolia Water Resources, 12: 39-40.

6. China Geological Environment Monitoring Institute, China Geological Environment Monitoring Groundwater Level Yearbook [M], China Land Press, 2006-2016

7. Wang, X.J., Bi, S.H., Gao, J., Zhao, H., Li, P., (2013) Thoughts on strict groundwater management and protection[J]. China Water Resources, 11: 7-9.

8. Mu, E.L., (2019) Discussion on the management of groundwater over-exploitation areas in my country $[\mathrm{J}]$. Groundwater, 39(06): 55-57 